\title{
CORRIGENDA
}

\section{Years of predictive testing for Huntington's disease: the experience of the UK Huntington's Prediction Consortium}

Sheharyar S Baig, Mark Strong, Elisabeth Rosser, Nicola V Taverner, Ruth Glew, Zosia Miedzybrodzka, Angus Clarke, David Craufurd, UK Huntington's Disease Prediction Consortium and Oliver W Quarrell

European Journal of Human Genetics (2017) 25, 1290; doi:10.1038/ejhg.2017.139

Correction to: European Journal of Human Genetics (2016) 24, 1396-1402; doi:10.1038/ejhg.2016.36; published online 11 May 2016

The formula on page 2 should read:

$4.2 \times$ prevalence $\times$ pop $(1994)$

$$
+\sum_{y=1995}^{2014} 4.2 \times \text { prevalence } / 18.8 \times \text { pop }(y) .
$$

The error is that the division by 18.8 is missing. The authors would like to apologise for their error.

\section{Glaucoma spectrum and age-related prevalence of individuals with FOXC1 and PITX2 variants}

Emmanuelle Souzeau, Owen M Siggs, Tiger Zhou, Anna Galanopoulos, Trevor Hodson, Deepa Taranath, Richard A Mills, John Landers, John Pater, James E Smith, James E Elder, Julian L Rait, Paul Giles, Vivek Phakey, Sandra E Staffieri, Lisa S Kearns, Andrew Dubowsky, David A Mackey, Alex W Hewitt, Jonathan B Ruddle, Kathryn P Burdon and Jamie E Craig

European Journal of Human Genetics (2017) 25, 1290; doi:10.1038/ejhg.2017.147

Correction to: European Journal of Human Genetics (2017) 25, 839-847; doi:10.1038/ejhg.2017.59; published online 3 May 2017

Post publication, the authors realised that the genomic coordinates for two cases were incorrect in their paper.
Table 2, case 19: the genomic coordinates should be g.110618453_ 110618454del and not g.110618315_110618316del.

Table 2, case 23: the genomic coordinates should be g.(110505201_ 110607760)_(110967245_111069815)del and not g.(111426357_ 111528916)_(111888401_111990971)del. 